\title{
Modeling the role of environmental variables on the population dynamics of the malaria vector Anopheles gambiae sensu stricto
}

\author{
Paul E Parham*, Diane Pople², Céline Christiansen-Jucht ${ }^{2}$, Steve Lindsay ${ }^{3}$, Wes Hinsley $^{2}$ and Edwin Michael ${ }^{4}$
}

\begin{abstract}
Background: The impact of weather and climate on malaria transmission has attracted considerable attention in recent years, yet uncertainties around future disease trends under climate change remain. Mathematical models provide powerful tools for addressing such questions and understanding the implications for interventions and eradication strategies, but these require realistic modeling of the vector population dynamics and its response to environmental variables.
\end{abstract}

Methods: Published and unpublished field and experimental data are used to develop new formulations for modeling the relationships between key aspects of vector ecology and environmental variables. These relationships are integrated within a validated deterministic model of Anopheles gambiae s.s. population dynamics to provide a valuable tool for understanding vector response to biotic and abiotic variables.

Results: A novel, parsimonious framework for assessing the effects of rainfall, cloudiness, wind speed, desiccation, temperature, relative humidity and density-dependence on vector abundance is developed, allowing ease of construction, analysis, and integration into malaria transmission models. Model validation shows good agreement with longitudinal vector abundance data from Tanzania, suggesting that recent malaria reductions in certain areas of Africa could be due to changing environmental conditions affecting vector populations.

Conclusions: Mathematical models provide a powerful, explanatory means of understanding the role of environmental variables on mosquito populations and hence for predicting future malaria transmission under global change. The framework developed provides a valuable advance in this respect, but also highlights key research gaps that need to be resolved if we are to better understand future malaria risk in vulnerable communities.

Keywords: Malaria, Anopheles gambiae s.s., Temperature, Rainfall, Density-dependence, Mathematical modeling, Climate change

\section{Background}

Among the potential effects of climate change on human health, the impact on infectious diseases has attracted increasing attention in recent years [1]. Vector-borne diseases (VBDs) are likely to be particularly vulnerable given the poikilothermic nature of vector survival and development, as well as the effects of temperature on pathogen development. Although the link between

\footnotetext{
* Correspondence: paul.parham@imperial.ac.uk

'Grantham Institute for Climate Change, Department of Infectious Disease Epidemiology, Imperial College, London W2 1PG, UK

Full list of author information is available at the end of the article
}

climatic variables and transmission has attracted interest for VBDs such as dengue and schistosomiasis, the combined global mortality of these diseases is less than $7 \%$ of that due to malaria [2], and this, combined with the significant effects of climatic variables on multiple stages of the transmission cycle, has led to malaria remaining an important focus of ongoing debate regarding climate change and VBDs $[3,4]$.

In the context of better understanding the role of weather and climate on transmission, two modeling approaches are possible. Statistical models use empirical relationships between climatic variables and past (or 
current) disease incidence (or prevalence) to predict future disease trends [5,6]. Mechanistic models, on the other hand, adopt a process-based approach, incorporating known biological, epidemiological and entomological relationships affecting vector and pathogen vital rates and formulating mathematically how these combine [7-9]. Both types of model have important roles to play in improving our understanding of climate-driven transmission changes, but the focus here is on exploiting the explanatory power of the latter.

A vital component in developing reliable VBD transmission models is establishing a realistic model of the vector population dynamics, yet only a few studies have explicitly modeled and parameterized the impact of climatic drivers on vector vital rates [8,10-12]. While these studies have greatly improved our understanding of the relative importance of temperature, rainfall and relative humidity $(\mathrm{RH})$ on vector populations, they also highlight the need to develop a comprehensive mathematical framework for analysing how a range of environmental factors, arising at different spatial scales, combine at the level of breeding sites to affect stage-specific vector abundance in malaria-affected regions.

This work aims to provide such a framework by formulating and parameterizing environment-vector relationships through surveying and modeling relevant experimental and field data, and incorporating these relationships within a low-dimensional, deterministic mathematical framework. Model simplicity permits ease of integration into malaria transmission models and the model is calibrated and validated against longitudinal Anopheles gambiae abundance data from Tanzania [13]. The model also highlights where further experimental and modeling work is required to improve parameterization, in addition to developing a framework readily generalized to different Anopheles species and other disease vectors.

\section{Methods}

Given that An. gambiae s.s. development and mortality depends on the life cycle stage and that field data available to parameterize mathematical models is often collected daily, a stage-structured, discrete-time model (with a daily time-step) is motivated. An alternative framework is based on physiological, rather than chronological, age and this has been adopted elsewhere $[7,8,10]$. In physiological age-structured models, progression through the life cycle is dependent on temperature conditions within a time-step and the minimum temperature for physiological development. However, while processes such as age-dependent mortality, heterogeneities in larval instars, and oviposition differences between gonotrophic cycles are more naturally incorporated within such approaches, there are several drawbacks of relevance to this article.
For a general physiological age-structured model of the form

$$
\mathbf{n}(t+1)=\mathbf{M}(\mathbf{n}, t) \mathbf{n}(t)
$$

where $\mathbf{n}=\left(n_{1} n_{2} n_{3} n_{4}\right)^{\mathrm{T}}$ and $\mathbf{M}$ is the projection matrix, the high-dimensional nature of $\mathbf{M}$ increases by an order of magnitude as temperature measurements become more precise. The dependence of development on other factors (such as RH for adults) also increases the complexity of $\mathbf{M}$, as well as making an implicit assumption about the linearity of development with temperature that is often violated. Thus, a low-dimensional approach is instead adopted here, providing a simple, structurally-parsimonious, deterministic model that more transparently illustrates the basic structure that may be built upon in future model development, is considerably easier to construct, analyse and interpret, and may be readily appended to malaria transmission models.

Immature $A n$. gambiae s.s. pass through three distinct aquatic stages (eggs, larvae (instars L1 to L4) and pupae) prior to adult development. Let $n_{i}(t)$ represent the number of vectors in state $i$ (where $i=1,2,3$ and 4 refers to eggs, larvae, pupae, and adults respectively). The exposed nature of breeding sites results in considerable vulnerability to environmental influences and the impacts of rainfall, temperature, and biotic effects on immature survival and development are considered here. For immature stages, the daily survival probability $p_{i}$ of stage $i$ is assumed to be determined by (independent) factors attributable to the mean daily water temperature $T_{W}\left({ }^{\circ} \mathrm{C}\right)$, cumulative daily rainfall $R_{t}(\mathrm{~mm})$, prolonged periods of desiccation $D$ (days), and density-dependence $D D$, so that

$$
p_{i}=p_{i}\left(T_{W}\right) p_{i}\left(R_{t}\right) p_{i}(D) p_{i}(D D)
$$

(where $i=1,2,3$ ), while, for adults, $p_{4}=p_{4}\left(T_{A}, R H\right)$ where $T_{A}$ is the mean daily air temperature $\left({ }^{\circ} \mathrm{C}\right)$ and $R H$ the relative humidity (\%). If $n_{i}(t)$ represents the number of (female) An. gambiae s.s. in stage $i$ at the breeding site at time $t$, then

$$
\begin{aligned}
& n_{1}(t+1)=P_{1} n_{1}(t)+F_{4} n_{4}(t), \\
& n_{2}(t+1)=P_{2} n_{2}(t)+G_{1} n_{1}(t), \\
& n_{3}(t+1)=P_{3} n_{3}(t)+G_{2} n_{2}(t), \\
& n_{4}(t+1)=P_{4} n_{4}(t)+G_{3} n_{3}(t)
\end{aligned}
$$

where $F_{4}$ is the average number of eggs laid per day per female adult, $P_{i}$ is the proportion of vectors surviving and remaining in stage $i$ in $t$ to $t+1$, and $G_{i}$ the proportion surviving and progressing from stage $i$ in $t$ to $t+1$. To calculate $P_{i}$ and $G_{i}$, the expressions from [14] are used, namely $P_{i}=\left(\frac{1-p_{i}^{d_{i}-1}}{1-p_{i}^{d_{i}}}\right) p_{i}$ and $G_{i}=\frac{p_{i}^{d_{i}}\left(1-p_{i}\right)}{1-p_{i}^{d_{i}}}$ (for all values of $i$ ), where $0 \leq p_{i} \leq 1$ is given by (2) and $d_{i}>1$ the 
average duration spent in stage $i$. To parameterize the model, the literature is reviewed to source relevant data, as well as using previously unpublished data, to develop, where appropriate, functional forms for $F_{4}, d_{i}$ and the components of $p_{i}$ in (2). The resultant population model (3) is then calibrated and validated against vector abundance data from [15].

\section{Results and discussion}

\section{Modelling breeding site hydrodynamics}

To capture the dependence of vector breeding site characteristics on environmental conditions, sites are modeled as right-centered cones to account for the increasing surface area of water available for oviposition as rainfall increases [16]. Let $V_{t}$ be the volume of water $(\mathrm{ml})$ within the site at time $t$ given a fixed site opening of surface area $A_{T}\left(\mathrm{~mm}^{2}\right), A^{\prime}$ the exposed surface area of water within the site after rainfall $\left(\mathrm{mm}^{2}\right.$ ) (where $A^{\prime} \leq A_{T}$ ) (which is then used to calculate the evaporation $E_{t}$ from the site at the end of day $t$ ), and $h$ ' the water depth after all daily rainfall (mm) (see Figure 1).

$$
\begin{gathered}
\text { For } V^{\prime} \leq V_{\max }=\frac{1}{3} A_{T} h^{\prime} / 1000, \\
V_{t+1}=V_{t}+\frac{A_{T} R_{t}}{1000}-\frac{A^{\prime} E_{t}}{1000},
\end{gathered}
$$

where $E_{t}$ is the evaporation from the site on day $t(\mathrm{~mm})$. Since the total volume of water (existing volume plus new rainfall) on day $t$ is $V^{\prime}=V_{t}+\frac{A_{T} R_{t}}{1000}$ and $A^{\prime}=$ $1000\left(\frac{3 V^{\prime}}{h^{\prime}}\right)$, substituting into (4) gives

$$
V_{t+1}=\left(V_{t}+\frac{A_{T} R_{t}}{1000}\right)\left(1-\frac{3 E_{t}}{h^{\prime}}\right)
$$

To determine $h$, consideration of the geometry of the cone before and after rainfall on day $t$ gives, using similar triangles, $V^{\prime} / V_{O}=\left(h^{\prime} / h_{O}\right)^{3}$ (where $V_{O}$ and $h_{O}$ are the initial volume and depth of water respectively). Rearranging for

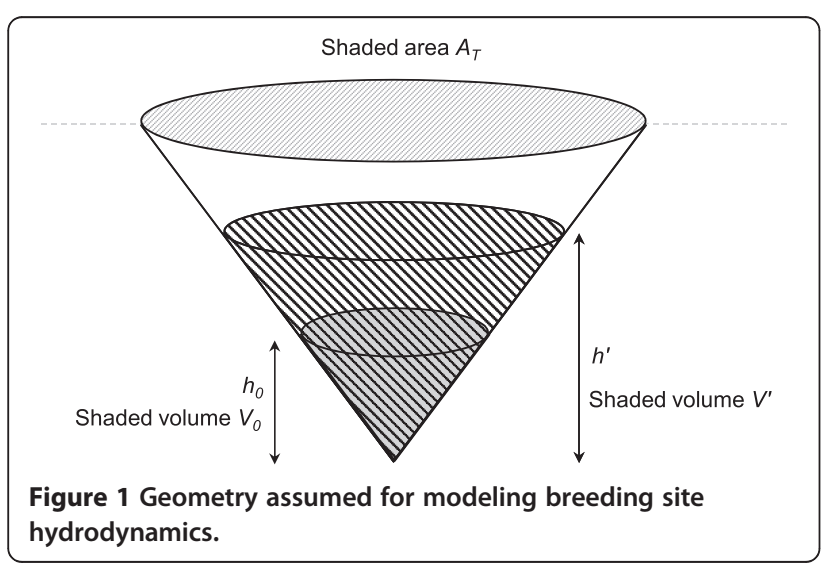

h', using the expression above for $V$, and substituting into (5) gives

$$
V_{t+1}=\left(V_{t}+\frac{A_{T} R_{t}}{1000}\right)\left(1-\frac{3 E_{t}}{h_{0}}\left(\frac{V_{0}}{V_{t}+\frac{A_{T} R_{t}}{1000}}\right)^{\frac{1}{3}}\right)
$$

To calculate $E_{t}$, the standard FAO Penman-Monteith method is used to first calculate the daily reference crop evapotranspiration $E T_{O}$ (mm/day) [17] as

$$
E T_{0}=\frac{0.408 \Delta\left(R_{n}-G\right)+900 \gamma U_{2}\left(e_{s}-e_{a}\right) /\left(T_{A}+273\right)}{\Delta+\gamma\left(1+0.34 U_{2}\right)} .
$$

Here, $\Delta$ is the slope of the vapour pressure curve $\left(\mathrm{kPa}^{\circ} \mathrm{C}^{-1}\right.$ ) (which depends on $T_{A}$ ), $R_{n}$ the daily net radiation transferred to the breeding site $\left(\mathrm{MJm}^{-2}\right.$ day $\left.^{-1}\right)$ (which, for a given location and day number, depends on the daily cloud fraction CF (through its relationship with the number of sunshine hours per day), dewpoint temperature $T_{D P}\left({ }^{\circ} \mathrm{C}\right)$, minimum daily temperature $T_{\text {min }}\left({ }^{\circ} \mathrm{C}\right)$ and maximum daily temperature $\left.T_{\max }\left({ }^{\circ} \mathrm{C}\right)\right)$, $G$ the soil heat flux $\left(\mathrm{MJm}^{-2}\right.$ day $\left.^{-1}\right), \gamma$ the psychrometric constant $\left(\mathrm{kPa}^{\circ} \mathrm{C}^{-1}\right)$ (constant for a given site), $U_{2}$ the wind speed at $2 \mathrm{~m}\left(\mathrm{~ms}^{-1}\right), e_{s}$ the saturation vapour pressure $(\mathrm{kPa})$ (dependent on $T_{\text {min }}$ and $T_{\text {max }}$ ), and $e_{a}$ the actual vapour pressure $(\mathrm{kPa})$ (dependent on $T_{D P}$ ). The climatic variables $R_{t}, T_{A}, T_{D P}$ and $C F$ are readily available from the ECMWF ERA-40 re-analysis dataset [18], while $U_{2}$ may be approximated from $U_{10}$ (the wind speed at $10 \mathrm{~m}$, available from ERA-40) using the conversion $U_{2}=0.748 U_{10}$ [17]. The outgoing heat conduction between the water body and surrounding soil $G$ is typically negligible compared to $R_{n}$ [17] and, as in [17], is neglected here.

Daily evaporation from an exposed breeding site is likely to differ from $E T_{O}$, however, due to differences in the reflectivity, heat capacity and typical microclimatic conditions of water bodies compared to crops. Pan evaporation $E_{p a n}$, the evaporation rate from pans filled with water and sunken into the ground, is more akin to breeding site conditions and hence $E_{t}$ can be estimated as

$$
E_{t}=E_{p a n}=\frac{E T_{0}}{K_{p}}
$$

where $K_{p}$ is an empirically-derived pan coefficient (dimensionless) that depends on the type of pan, breeding site surroundings, $R H$ (obtained from $R H=$ $\left.100 \exp \left(17.27 T_{D P} /\left(237.3+T_{D P}\right)-17.27 T_{A} /\left(237.3+T_{A}\right)\right)\right)$ and $U_{2}$. Although immature An. gambiae s.s. typically prefer clear water, examples of breeding within turbid waters also exist [19], but the turbidity of water does not typically affect $E T_{O}$ (and hence $E_{t}$ ) by more than $5 \%$ [17], so this is ignored here. Daily values of $K_{p}$ are 
estimated using the empirical tables for Colorado sunken pans (with $1 \mathrm{~m}$ radius dry fetch) in [17] based on daily values of $R H$ and $U_{2}$. A summary of model parameters is given in Table 1.

\section{Environmental influences on immature development Rainfall}

Rainfall typically correlates strongly with vector abundance and malaria prevalence [20]. Anopheline species often differ in their habitat preference - An. gambiae s.s. prefer to breed in small, shallow, temporary rain pools or stagnant bodies of water fully exposed to the sun (such as hoof marks, tyre tracks or other pools created during land use changes) [21], while other species within the $A n$. gambiae complex differ in their preference for freshwater, brackish and saline water [19]. To capture the dependence of oviposition behaviour on environmental conditions, let $N_{E P}$ and $N_{E O}$ be the number of eggs per female per oviposition produced and laid (respectively), so that

$$
N_{E O}=f_{t} N_{E P}
$$

where $0 \leq f_{t} \leq 1$ is the proportion of eggs laid given the environmental conditions on day t. An. gambiae s.s. oviposition may be influenced by two signals - a chemical cue directing the suitability of habitat water for oviposition

Table 1 Key model variables, parameters, and climatic variables

\begin{tabular}{|c|c|}
\hline Quantity & Definition \\
\hline$\overline{n_{i}(t)}$ & $\begin{array}{l}\text { The number of An. gambiae s.s. } \\
\text { in stage } i \text { on day } t \text { (where } i=1,2,3 \text {, } \\
\text { and } 4 \text { corresponds to eggs, larvae, } \\
\text { pupae, and adults respectively) }\end{array}$ \\
\hline$p_{i}$ & The daily survival probability of stage $i$ \\
\hline$d_{i}$ & The average duration spent in stage $i$ (days) \\
\hline$V_{t}$ & The volume of the breeding site on day $t(\mathrm{ml})$ \\
\hline$E_{t}$ & $\begin{array}{l}\text { Evaporation from the breeding } \\
\text { site on day } t(\mathrm{~mm})\end{array}$ \\
\hline$D$ & $\begin{array}{l}\text { The number of consecutive days } \\
\text { without water in the breeding site (days) }\end{array}$ \\
\hline$T_{A}$ & Daily mean air temperature $\left({ }^{\circ} \mathrm{C}\right)$ \\
\hline$T_{W}$ & $\begin{array}{l}\text { Daily mean water temperature in the } \\
\text { breeding site }\left({ }^{\circ} \mathrm{C}\right)\end{array}$ \\
\hline$R_{t}$ & Total rainfall on day $t(\mathrm{~mm})$ \\
\hline$T_{D P}$ & Dew-point temperature $\left({ }^{\circ} \mathrm{C}\right)$ \\
\hline $\mathrm{RH}$ & $\begin{array}{l}\text { Relative humidity (\%) (can be calculated } \\
\text { from knowledge of } T_{A} \text { and } T_{D P} \text { ) }\end{array}$ \\
\hline$C F$ & Cloud fraction \\
\hline$T_{\min }$ & Minimum daily temperature $\left({ }^{\circ} \mathrm{C}\right)$ \\
\hline$T_{\max }$ & Maximum daily temperature $\left({ }^{\circ} \mathrm{C}\right)$ \\
\hline$U_{2}$ & Wind speed at $2 \mathrm{~m}\left(\mathrm{~ms}^{-1}\right)$ \\
\hline
\end{tabular}

and the existing density of juveniles present [22-25]. Dependence on the latter is quantified using the oviposition index $O I$ introduced in [26]. Using [24] and refitting to find $O I$ as a function of the number of immature per $\mathrm{ml}$ $\rho_{t}$ (using data on L1 and L2 instars) gives

$$
O I_{t}=1.037 \exp \left(-6\left(\rho_{t}-0.317\right)^{2}\right)-0.616
$$

It is shown in [24] that this does not depend on the number of eggs present, while [22] demonstrates that pupae presence also has no significant influence on oviposition choice. Thus, for the model here, where $n_{i}(t)$ represents the number of vectors in stage $i$, the relevant density is $\rho_{t}=n_{2}(t) / V_{t}$. Hence, since $O I=$ $\left(N_{t}-N_{s}\right) /\left(N_{T}+N_{s}\right)$, where $N_{T}$ and $N_{S}$ are the number of eggs laid in the test substrate (pool water with larvae) and control substrate (pool water without larvae) respectively,

$$
f_{t}=\frac{N_{E O}}{N_{E P}}=\frac{N_{t}}{N_{T}+N_{S}}=\frac{1}{2}\left(O I_{t}+1\right),
$$

whereupon substituting from (10), and assuming that L3 and L4 presence has the same effect on site-attractiveness,

$$
f_{t}=0.51 \exp \left(-6\left(n_{2}(t) / V_{t}-0.317\right)^{2}\right)+0.192 \text {. }
$$

In addition to creating breeding sites and influencing the characteristics of existing pools, high levels of rainfall have been associated with significant immature mortality, either due to flushing from habitats or from secondary effects [27]. These are aggregated here into total rainfall-induced mortality, modeling the decrease in survivorship by letting $p_{i}\left(R_{t}\right)$ represent the daily survival probability of immatures in stage $i$ given rainfall $R_{t}$. It is assumed that $p_{i}\left(R_{t}\right)=\exp \left(-\sigma_{i} R_{t}\right)(i=1,2,3)$ where $\sigma_{i}$ quantifies the decrease in survival of stage $i$. Given the focus on L1 and L4 larvae in [27] and the absence of data elsewhere on egg and pupal mortality due to rainfall, eggs and pupae are assumed to respond similarly to L1 and L4 larvae respectively (although pupal response may differ from L4 larvae in reality due to their ventral air space that aids buoyancy, yet significantly increases mortality if this hydrostatic balance is disrupted [28]). Assuming average L1 and L4 losses of $17.5 \%$ and $4.8 \%$ per night respectively over the study period with $207 \mathrm{~mm}$ rainfall across 26 rainfall nights (K. P. Paaijmans, pers. comm.) gives $\sigma_{1}=0.0242 \mathrm{~mm}^{-1}$ and $\sigma_{3}=$ $0.00618 \mathrm{~mm}^{-1}$. Given that the model here does not distinguish between larval instars, the average duration spent in each instar (as a function of $T_{W}$ ) is accounted for by interpolating between L1 and L4 mortalities in [27] to determine L2 and L3 survival, whereupon 
averaging over all temperatures gives $\sigma_{2}=0.0127 \mathrm{~mm}^{-1}$ (Figure 2a).

The prolonged absence of water also affects immature longevity; anopheline egg survival in desiccating conditions is two to three weeks [29], while An. gambiae s.l. eggs are viable for up to 12 days without water [30]. To model the decrease in egg viability in dry habitats, the findings of [31] are used, which demonstrate that the duration of exposure to desiccating conditions is a better measure of egg viability than soil moisture content. If $p_{i}(D)$ is the daily survival probability of stage $i$ given $D$ days without water, the functional form $p_{i}(D)=2 \exp$ $\left(-\omega_{i} D\right) /\left(1+\exp \left(-\omega_{i} D\right)\right)(i=1,2,3)$ is fitted, where $\omega_{i}$ quantifies the sensitivity of stage $i$ to desiccation and the functional form ensures that survival is near unity when $D$ is small and approaches zero as desiccation increases. Least-squares estimation using field populations under medium-moisture conditions gives $\omega_{i}=$ 0.405 days $^{-1}\left(R^{2}>0.99\right)$. Survival of larvae and pupae may be similarly parameterized using [29], which demonstrates that L4 larvae survive significantly better than L1, L2 and L3 instars in such conditions - weighting by the average

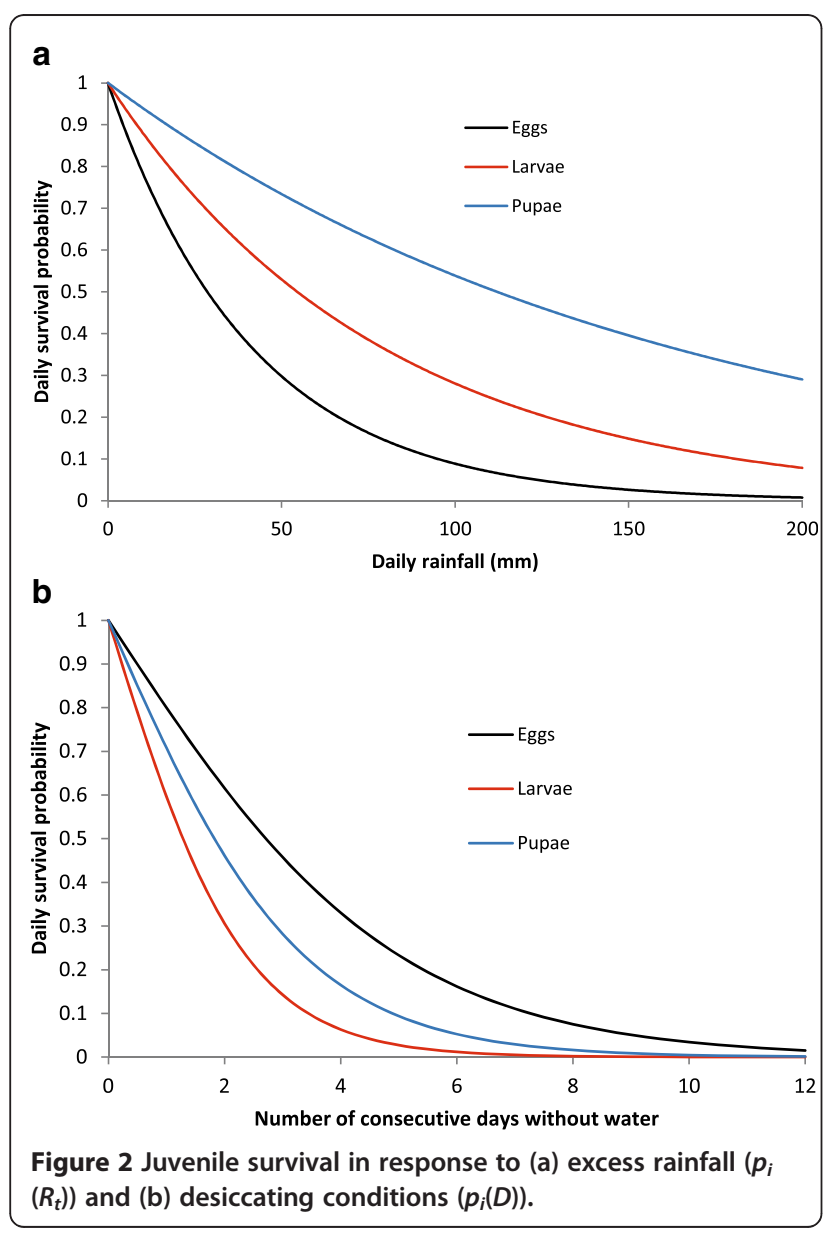

duration in each instar stage gives $\omega_{2}=0.855$ days $^{-1}\left(R^{2}=\right.$ 0.97). In the absence of data on pupal survival, pupae are assumed to demonstrate a similar response to L4 larvae, whereupon using [29] gives $\omega_{2}=0.602$ days $^{-1}\left(R^{2}=0.94\right)$ (Figure 2b).

\section{Temperature}

Despite the strong influence of water temperature on immature populations, few detailed experimental studies have been undertaken. The model here requires the daily survival probability $p_{i}\left(T_{W}\right)$ and stage duration $d_{i}\left(T_{W}\right)$ for each $i$. For all three stages, age-independent mortality is assumed and hence $p_{i}\left(T_{W}\right)=\exp \left(-1 / d_{i}\left(T_{W}\right)\right)$ (Figure $3 \mathrm{a}$ and $3 \mathrm{~b}$ ).

Egg survival is poor outside $10-40^{\circ} \mathrm{C}$ and [32] find that no An. gambiae s.s. eggs survive more than five hours at or above $41^{\circ} \mathrm{C}$, with survival decreasing exponentially beyond $40^{\circ} \mathrm{C}$. For egg development time $d_{1}\left(T_{W}\right)$, the functional form of [33], with the corrected coefficients of Bayoh and Lindsay (unpublished data) (Table 2), is adopted.

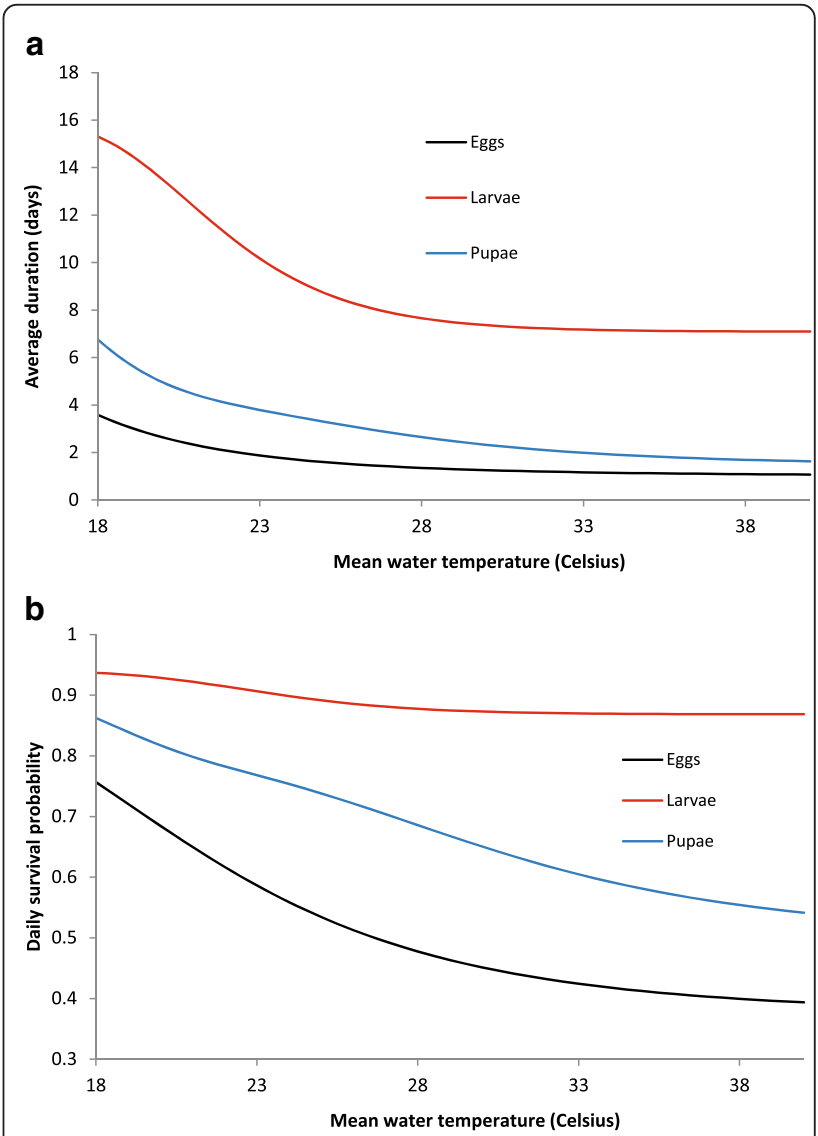

Figure 3 (a) Average development time $d_{i}\left(T_{W}\right)$ and (b) survival probability $p_{i}\left(T_{W}\right)$ of immature stage $i$. 
Of the juvenile stages, larval survival demonstrates the strongest dependence on temperature and the effect of competition between An. gambiae s.s. and Anopheles arabiensis on temperature-dependent survival has been examined [34]. The relationship between survival, development and water temperature, and age-dependent mortality, for An. gambiae s.s. is considered in [35]. Larval duration is parameterized as a function of $T_{W}$ in [5], but this is An. gambiae s.l., rather than An. gambiae s.s. Moreover, this parameterization is based only on temperatures between 23.0 and $32.8^{\circ} \mathrm{C}$ and extrapolating to temperature extremes gives inconsistent results with experimental findings in [33] (such as development times around 30 days at $18^{\circ} \mathrm{C}$ in the former compared to 15 days in the latter). While [10] provides a literature survey of larval development times as a function of $T_{W}$, eight of the twelve data points for An. gambiae s.s. are calculated from [33] on the assumption of eggs and pupae developing within one day, which is inconsistent with experimental data in the latter. The revised coefficients from Bayoh and Lindsay (unpublished data) are therefore used to determine $d_{2}\left(T_{W}\right)$.

Aside from the work of [36] on the effects of temperatures from 21.2 to $29.5^{\circ} \mathrm{C}$ on An. gambiae s.l. pupal mortality and [33], there is little experimental data to parameterize pupal development and survival. The latter, with the corrected values in Bayoh and Lindsay (unpublished data), are therefore used to parameterize $d_{3}\left(T_{W}\right)$.

Finally, it is important to note the importance of using water temperature to calculate juvenile survival and development, rather than air temperature. The difference between mean daily water and air temperatures is typically around $3-6^{\circ} \mathrm{C}$ depending on factors such as breeding site dimensions, microclimate and weather conditions $[32,37]$. To account for this, it is assumed that $T_{W}=$ $T_{A}+\Delta T$, where $\Delta T>0$ is assumed to capture all thermodynamic processes taking place at breeding sites leading to a difference between mean water and air temperatures. Lower and upper temperature thresholds for juveniles are taken from [33].

\section{Predation and density-dependence}

Density-dependent juvenile mortality arises from several sources. Body size and intra-species competition for resources, together with inter-species competition, significantly affect the population dynamics of many mosquito species and recent work has demonstrated the importance of larval density on juvenile Anopheles development and ecology [38]. Here, only within-stage densitydependent mortality is assumed and the potential effects of juvenile density on adult longevity or fertility are not considered. Figure 4 demonstrates the dependence of larval survival on existing larval density ( $\mathrm{H}$ Tsila,
Table 2 Average duration $d_{i}\left(T_{W}\right)$ of immature stage $i$ at water temperature $T_{W}$ (from Bayoh and Lindsay (unpublished data))

\begin{tabular}{lc}
\hline Parameter & Functional form \\
\hline$d_{1}\left(T_{W}\right)$ & $1.011+20.212\left(1+\left(\frac{T_{W}}{12.096}\right)^{4.839}\right)^{-1}$ \\
$d_{2}\left(T_{W}\right)$ & $8.130+13.794\left(1+\left(\frac{T_{W}}{12.096}\right)^{4.839}\right)^{-1}-d_{1}\left(T_{W}\right)$ \\
$d_{3}\left(T_{W}\right)$ & $8.560+20.654\left(1+\left(\frac{T_{W}}{19.759}\right)^{6.827}\right)^{-1}-d_{2}\left(T_{W}\right)$
\end{tabular}

unpublished data), while field populations of Anopheles larvae typically demonstrate low densities (for species that do not breed in tree holes or containers) - some field estimates suggest densities of less than $0.3 / \mathrm{ml}$ in rice fields, pools and small ponds [36,39], while others suggest densities around 0.02-0.06 larvae/ml and 1.5 lar$\mathrm{vae} / \mathrm{ml}[40,41]$ (respectively). Comparing these estimates with Figure 4 suggests that larval densities in field populations occur in regimes where intra-species competition for resources is minimal, suggesting that densitydependent mortality is most likely due to predation, although cannibalism may also occur [42].

Field observations also suggest the spatial aggregation of juvenile An. gambiae s.l., with larvae typically distributed negative binomially [43]. To model the effects of density-dependence, these observations are incorporated within application of the framework of [44] for developing first principles population models given knowledge of intra-species competition and spatial distribution. For larval populations following a negative binomial distribution and demonstrating predominantly contest competition (given the dominance of predation, also consistent with findings elsewhere such as [40]), [44] demonstrates that if $X_{t}$ is the population size at time $t$,

$$
X_{t+1}=b m\left(1-\frac{\lambda^{\lambda}}{\left(\lambda+X_{t} / m\right)^{\lambda}}\right),
$$

where $m$ is the number of resource sites across which the population is distributed, $\lambda$ the aggregation parameter of the negative binomial distribution and $b$ a positive constant. The value of $\lambda$ is calculated by averaging the aggregation parameters from the five experiments in [43] for which the negative binomial provides the best fit to obtain $\lambda=1.5$. To determine $b$, consider, without loss of generality, an arbitrary one litre volume of water within a breeding site and divide this into $1 \mathrm{ml}$ blocks (so $m=1000$ ). The observed difference in juvenile mortality between field data and the contribution from temperature and rainfall is attributed to density- 


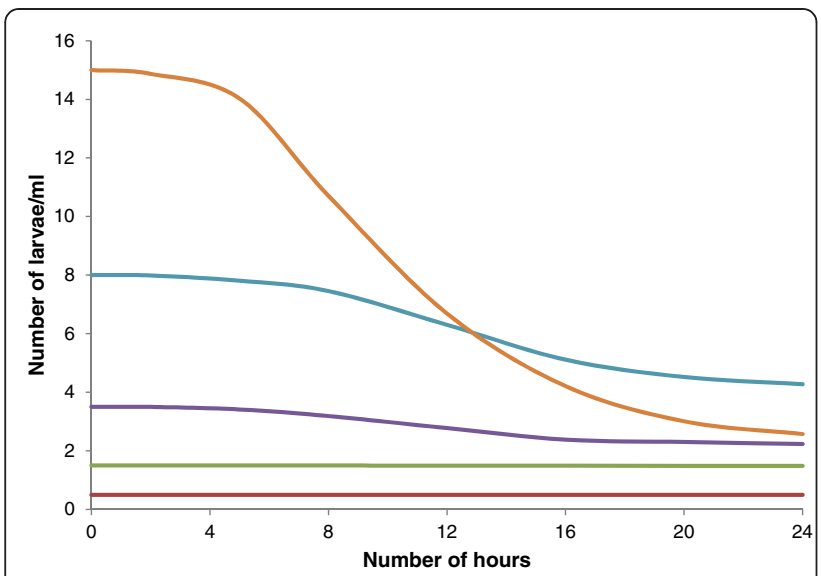

Figure 4 The daily survival of larvae as a function of initial density.

dependence. Given that the datasets used consider survival from L1 instars and that the duration of field studies is often longer than the development time from L1 to pupae, it is assumed that predation reduces larval and pupal survival and acts identically on both stages. Since the population affected is $n_{2}(t)+n_{3}(t)$, the number of larvae and pupae per litre is $N_{23}(t)=$ $1000\left(n_{2}(t)+n_{3}(t)\right) / V_{t}$ and $p_{i}(D D)=X_{t+1} / X_{t}$, the daily larval and pupal survival probability due to density-dependence, $p_{2}(D D)$ and $p_{3}(D D)$, is

$$
p_{i}(D D)=\frac{b m}{N_{23}(t)}\left(1-\frac{\lambda^{\lambda}}{\left(\lambda+N_{23}(t) / m\right)^{\lambda}}\right)
$$

for $i=2$ and 3. If $n_{2}(t)+n_{3}(t)=0$ or $V_{t}=0, p_{i}(D D)$ is assumed to be unity. Predation on eggs is assumed to be negligible by comparison and anopheline rice-field survival data from [39], [41] and [45] is used to provide seven independent datasets to fit $b$ at $\Delta T=3^{\circ} \mathrm{C}, 4^{\circ} \mathrm{C}, 5^{\circ} \mathrm{C}$ and $6^{\circ} \mathrm{C}$. For each dataset, air temperature and rainfall data from the nearest meteorological station (using [46] and where missing values are interpolated) are used to calculate the daily survival and development of larvae and pupae due to climatic influences (assuming fixed vector density and assuming no desiccation effects for rice fields) and estimate the additional mortality required to agree with the study data (attributed to $p_{i}(D D)$ ). Two approaches are adopted, namely to (a) calculate the number of juveniles remaining after a fixed number of days (determined by the study design), and (b) track the number of cohort larvae and pupae until less than $0.05 \%$ of the original population remain. For method (a), where experimental dates are not specified, $b$ is calculated for a range of plausible start dates and the average computed. No significant difference in calculating $b$ using these methods is found and $b=0.89$ for $\Delta T=3^{\circ} \mathrm{C}$ and 0.88 for $\Delta T=4^{\circ} \mathrm{C}, 5^{\circ} \mathrm{C}$ and $6^{\circ} \mathrm{C}$.

\section{Environmental influences on adult development}

The survival of adult Anopheles is sensitive to temperature and $\mathrm{RH}$, although few experimental studies have examined this in detail and [11] have recently undertaken a review of parameterization work to date. Although the fitting of [47] has been used in work examining the effects of climatic variables on malaria transmission (such as [8]), this parameterization is inconsistent with [48] demonstrating that $A n$. gambiae s.s. cannot survive longer than one day at $40^{\circ} \mathrm{C}$. Thus, the majority of modeling studies to date investigating malaria transmission under changing environmental conditions $[5,7,9,49]$ use

$$
p_{4}\left(T_{A}\right)=\exp \left(-1 /\left(-0.03 T_{A}^{2}+1.31 T_{A}-4.4\right)\right),
$$

despite its basis on fitting a three-parameter function to three data points in the range $9-40^{\circ} \mathrm{C}$ [9] (with the $40^{\circ} \mathrm{C}$ point inconsistent with [48]). This relationship assumes no adverse effects of $\mathrm{RH}$ on mortality, which is unlikely given that $\mathrm{RH}<50 \%$ leads to significantly reduced survival [50]. Field observations of $A n$. gambiae adults are only approximately consistent with (18), but reflect the relatively high survival at $22-30^{\circ} \mathrm{C}$ [36].

To obtain a more systematic fitting, experimental data from Bayoh and Lindsay (unpublished data), who estimate survival thresholds of $5^{\circ} \mathrm{C}$ and $40^{\circ} \mathrm{C}$ and, within this range, examine the effects of temperature and $\mathrm{RH}$ on mortality, are used. Age-independent survival is assumed and $p_{4}\left(T_{A}, R H\right)$ fitted given mean female survival times at $5-40^{\circ} \mathrm{C}$ inclusive (in $5^{\circ} \mathrm{C}$ intervals) and 40 $100 \% \mathrm{RH}$ (at $20 \%$ intervals) to obtain

$$
p_{4}\left(T_{A}, R H\right)=\exp \left(-1 /\left(\beta_{2} T_{A}^{2}+\beta_{1} T_{A}+\beta_{0}\right)\right)
$$

where $\beta_{2}=4.00 \times 10^{-6} R H^{2}-1.09 \times 10^{-3} R H-0.0255$, $\beta_{1}=-2.32 \times 10^{-4} R H^{2}+0.0515 R H+1.06$ and $\beta_{0}=$ $0.00113 R H^{2}-0.158 R H-6.61$ (Figure $5 a$ ). Survival outside this temperature range is assumed to be zero, but no $\mathrm{RH}$ thresholds are assumed.

The duration of the gonotrophic cycle $G_{c}$ is also temperature-dependent and [9] parameterizes this as $G_{c}\left(T_{A}\right)=D_{M} /\left(T_{A}-T_{M}\right)$ where $D_{M}=36.5^{\circ} \mathrm{C}$ days and $T_{M}=$ $9.9^{\circ} \mathrm{C}$. An alternative functional form is given by [11] as

$$
G_{c}\left(T_{A}\right)=1+\frac{D_{E}}{T_{A}-T_{E}}
$$

where $D_{E}=37.1^{\circ} \mathrm{C}$ days and $T_{E}=7.7^{\circ} \mathrm{C}$. Comparing these formulations, the latter gives longer gonotrophic cycles 


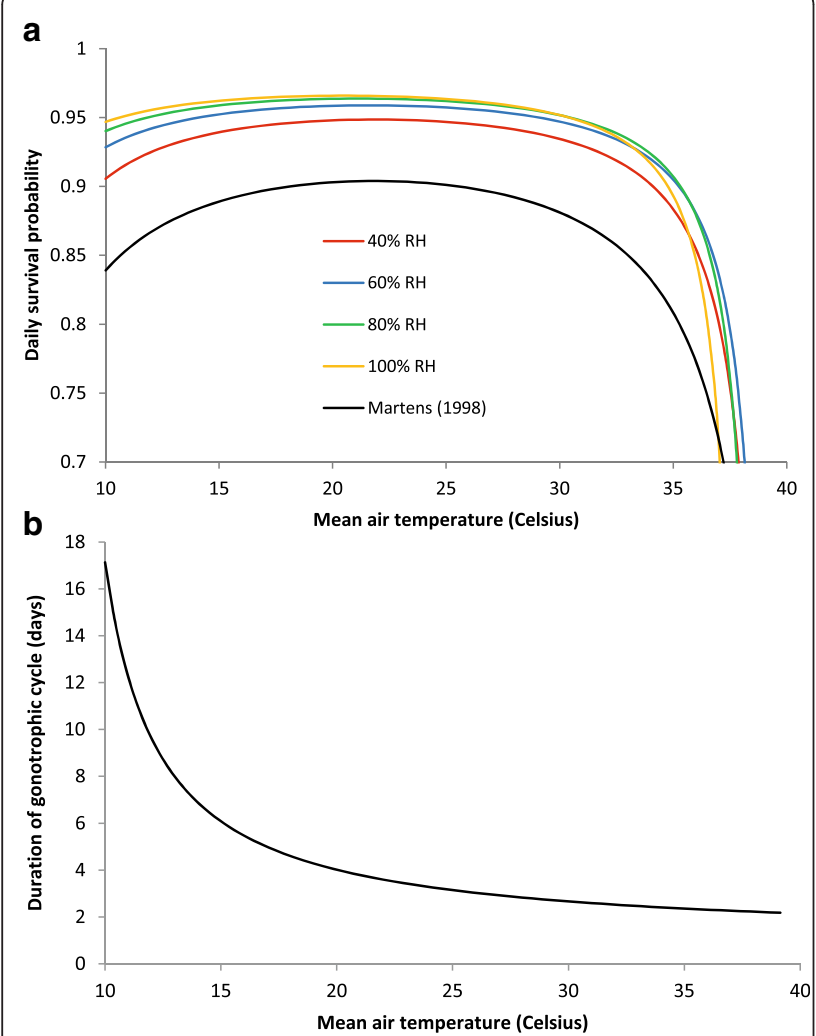

Figure 5 (a) Daily (female) adult survival $p_{4}\left(T_{A}, R H\right)$ versus the parameterization of [9]. (b) $G_{c}\left(T_{A}\right)$ from (20).

at temperatures above $17.6^{\circ} \mathrm{C}$, the regime generally of interest. On the basis of better agreement with [51], (20) is adopted (Figure $5 \mathrm{~b}$ ). To calculate $F_{4}, d_{4} / G_{c}\left(T_{A}\right)$ gives the average number of ovipositions per adult across her lifetime. If the average number of eggs per oviposition is $N_{E O}=f_{t} N_{E P}$, the average number of eggs laid over her lifetime is $d_{4} N_{E O} / G_{c}\left(T_{A}\right)$, so that $F_{4}$, the average number laid per day, is

$$
F_{4}=\frac{f_{t} N_{E P}}{G_{c}\left(T_{A}\right)} .
$$

Given the absence of age-structure in this model, each gonotrophic cycle is assumed to be of equal duration for all adults and produce the same number of eggs, although studies have shown variation in both [52].

No direct influences of rainfall on adult survival are assumed (with indirect effects through changes in RH captured by (19)) and adult survival is assumed to be densityindependent following [53] and the weak, but statistically significant, relationship between adult density and survivorship in [15]. There is some evidence of predation on adult An. gambiae s.l. at oviposition sites, with the severity potentially depending on the type of site [39], but there are few quantitative studies in this respect.

\section{Model calibration and validation}

To assess performance, the model is calibrated and validated against longitudinal An. gambiae s.l. abundance data from [13] collected in an environment free of vector controls. Data on $T_{A}, T_{D P}$ (for calculation of $R H$ ), (low) cloud fraction $C F$, and the horizontal and vertical components of $10 \mathrm{~m}$ wind speed (to calculate $U_{2}$ ) are taken from the ERA-40 re-analysis dataset [18] for the rural community in Masaika, Tanzania (516' 0" S, 38 49' $60^{\prime \prime} \mathrm{E}$ ) (with the nearest ERA-40 point at $5^{\circ}, 0^{\prime} 0^{\prime \prime} \mathrm{S}, 37^{\circ}$ 30 ' 0" E). Rainfall data from the Maji Depot Tanga Rainfall station (at 54' 58" S, 395' 21" E), approximately $35 \mathrm{~km}$ from Masaika, is used when available (see [13]), with missing data taken from [18]. Since the daily values of $T_{\min }$ and $T_{\max }$ are not available from [18], we derive empirical relationships between $T_{A}$ and these variables using data from the nearest meteorological station (Tanga at $5^{\circ} 4^{\prime} 48^{\prime \prime} \mathrm{S}, 39^{\circ} 4^{\prime} 12^{\prime \prime} \mathrm{E}$ ), approximately $34 \mathrm{~km}$ from the study site, and apply these relationships $\left(T_{\min }=\right.$ $0.724 T_{A}+14.4$, with $R^{2}=0.53$, and $T_{\max }=0.728 T_{A}+$ 28.3, with $\left.R^{2}=0.61\right)$ to ERA-40 data on $T_{A}$ to estimate the associated values of $T_{\min }$ and $T_{\max }$.

Daily abundance data is available from 06/07/1998 to 30/11/2001 (approximately 41 months), consisting of the number of adult An. gambiae s.l. caught in CDC light traps; further details on mosquito collection and experimental procedures are given in [13]. The model is calibrated using the first twenty months of complete monthly data (August 1998 to March 2000 inclusive) and validated over the subsequent twenty months (April 2000 to November 2001 inclusive). The variation in $T_{A}$ and $R H$ over the calibration and validation periods is shown in Figure 6. Data on the average number of $A n$. gambiae s.l. caught per trap is available for each weekday in the period (aside from short breaks for public holidays), but not at weekends. Given the daily time-step nature of the model, weekend abundance is estimated using linear interpolation and these values appended to the weekday values. This data is then aggregated by month and the model fitted at this scale. A minimum 365 day burn-in period is applied to remove early model transients.

For model calibration, the average number of adult $A n$. gambiae s.l. per light trap is fitted to model output after the burn-in period. To account for the difference in scale between data and the model, the scaled fecundity $\bar{F}_{4}=\alpha_{1} F_{4}$ and adult $A n$. gambiae s.s. abundance $\bar{n}_{4}=\alpha_{2} n_{4}$ are defined and just three parameters fitted over the calibration period - the scale parameters $\alpha_{1}$ and $\alpha_{2}$, and $\Delta T$. All other parameters are derived from parameterizations in this paper and local breeding site properties (altitude and latitude). It is assumed that $N_{E P}=120$ (based on model calibration in [7]) and breeding site dimensions consistent with the characteristics of typical An. gambiae s.s. habitats (in the presence of multiple An. gambiae s.l. species given the 


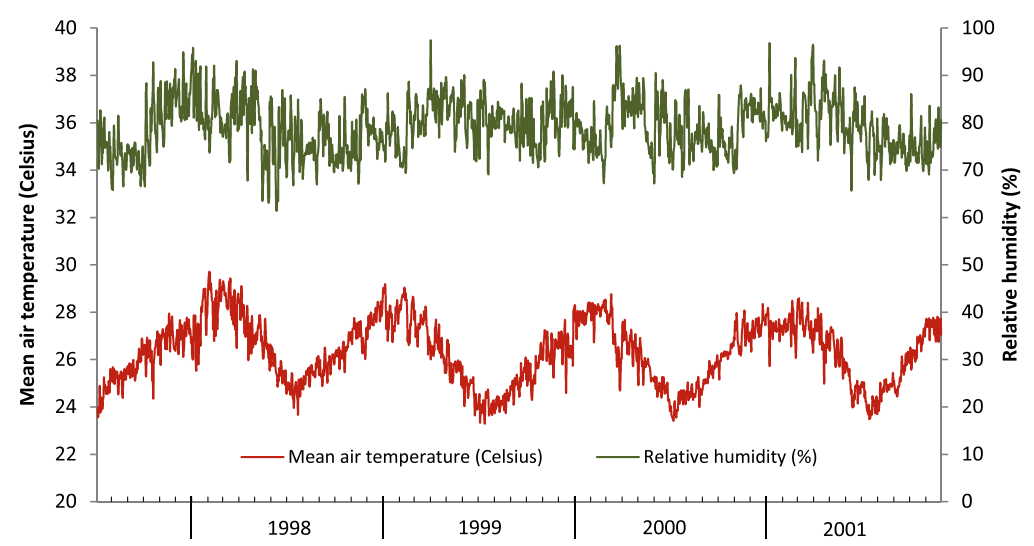

Figure 6 Daily air temperature and relative humidity over the calibration and validation periods.

collection of multiple Anopheles species in data collection in [13]) reported in [21], namely $A_{T}=1.79 \times 10^{6} \mathrm{~mm}^{2}$ and $h_{0}=97 \mathrm{~mm}$. An initial water volume of 1 litre is assumed $\left(V_{O}=1000 \mathrm{ml}\right)$. Model fit to data is found to be independent of the initial conditions, so 100 mosquitoes are arbitrarily initially assumed to be in each lifecycle stage.

Fitting the model using least-squares to the 20 month calibration data gives the best-fit parameters $\alpha_{1}=$ $141.612, \alpha_{2}=0.030$ and $\Delta T=6.9^{\circ} \mathrm{C}\left(R^{2}=0.84\right)$. Running the model for a further 20 months with these parameters and assessing the goodness-of-fit gives $R^{2}=0.50$ across the validation period (Figure 7 ). The model is encouragingly able to capture the overall decline in $A n$. gambiae s.l. abundance in Masaika reported in [13] across the calibration and validation periods, as well as the general seasonal trend (although the timing of the two abundance peaks in the validation period are underestimated by one month in both cases, as well as the magnitude of the peaks). The water volume within the breeding site over time (with these best-fit parameters) is shown in Figure 8, while the immature population dynamics, and estimated daily water temperature, are plotted in Figure 9. Alternatively fitting the model across the entire 40 months of data (Figure 10) gives $R^{2}=0.70$ (with $\alpha_{1}=$ 280.486, $\alpha_{2}=0.026$ and $\Delta T=6.1^{\circ} \mathrm{C}$ ) and, in this case, the timing of two of the three seasonal peaks are correctly predicted, as well as the approximate severity of these peaks. The fitted values of $\Delta T=6.9^{\circ} \mathrm{C}$ and $6.1^{\circ} \mathrm{C}$ are slightly greater than typical $\Delta T$ values observed in the field (values in [37], for example, lie in the range 4.0-6.1 ${ }^{\circ}$ $\mathrm{C}$ on clear days for three different sized pools), and this reflects the simplified nature of the $T_{W}=T_{A}+\Delta T$ formulation and fitting a single mean value of $\Delta T$ across annual timescales. Future refinements will improve this

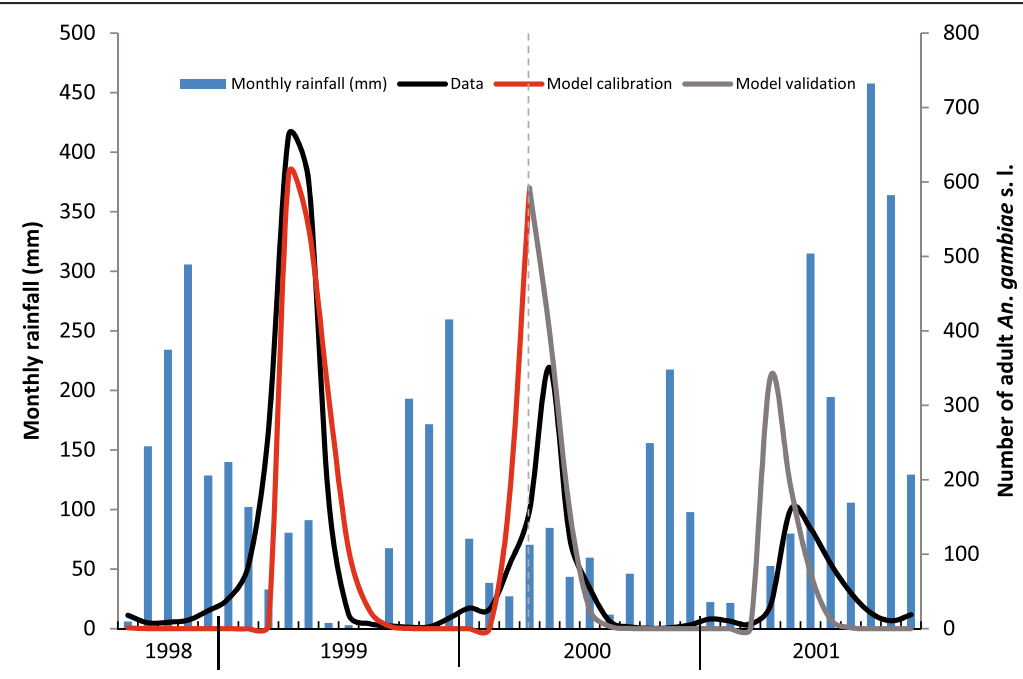

Figure 7 Model calibration (August 1998 to March 2000 inclusive) and validation (April 2000 to November 2001 inclusive) versus adult An. gambiae s.l. abundance data from [13]. 


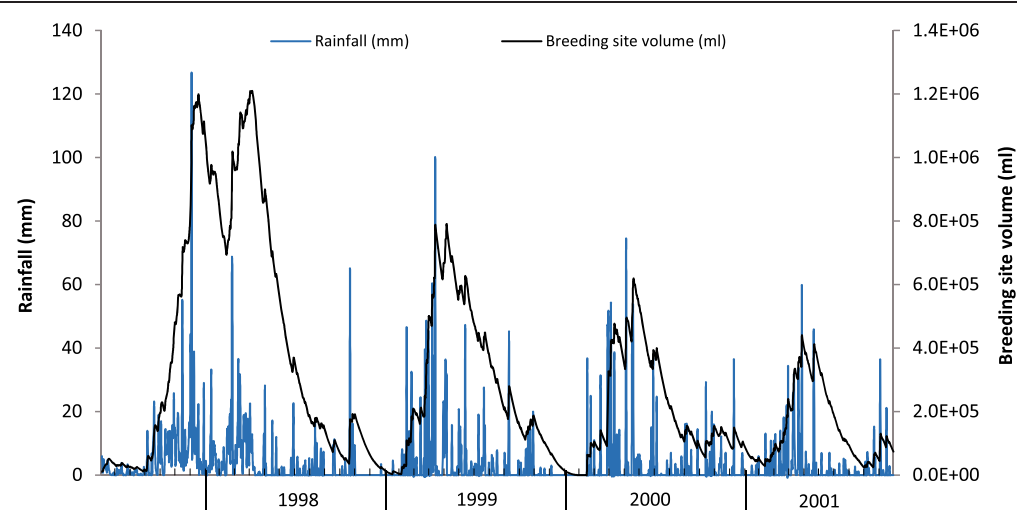

Figure 8 Daily rainfall and breeding site water volume over the calibration and validation periods.

component of the model by calculating $\Delta T$ from thermodynamical principles based on daily weather conditions and this is expected to further improve model fit. Nonetheless, the model offers the potential for mechanistic insight into vector response to temperature, rainfall, $\mathrm{RH}$, wind speed and cloudiness, and hence how future changes in these variables may affect mosquito dynamics. The results suggest that the observed decline in vector numbers (and malaria) reported in [13] could, in turn, be due to long-term changes in environmental conditions. Further model analysis (such as application of the methods of matrix population modeling [54]) will provide valuable insight into the dominant environmental variables influencing the observed changes in vector numbers, as well as furthering our understanding of the dominant drivers on short and long-term timescales.
While such analysis is beyond the scope of this paper and will follow in a forthcoming article, these results highlight the explanatory power of validated mathematical models and their role in evaluating the effects of temporal changes in weather and climate on vector dynamics and, ultimately, disease transmission.

\section{Conclusions}

Along with An. arabiensis and Anopheles funestus, An. gambiae s.s. is one of the principal malaria vectors in Africa [19] and understanding its ecology and dynamics is vital in better understanding the associated impact on malaria transmission and the prospects for eradication [55], as well as the effectiveness of vector controls in different communities and settings. Vector population dynamics are driven by a range of biotic and abiotic factors and clarifying the

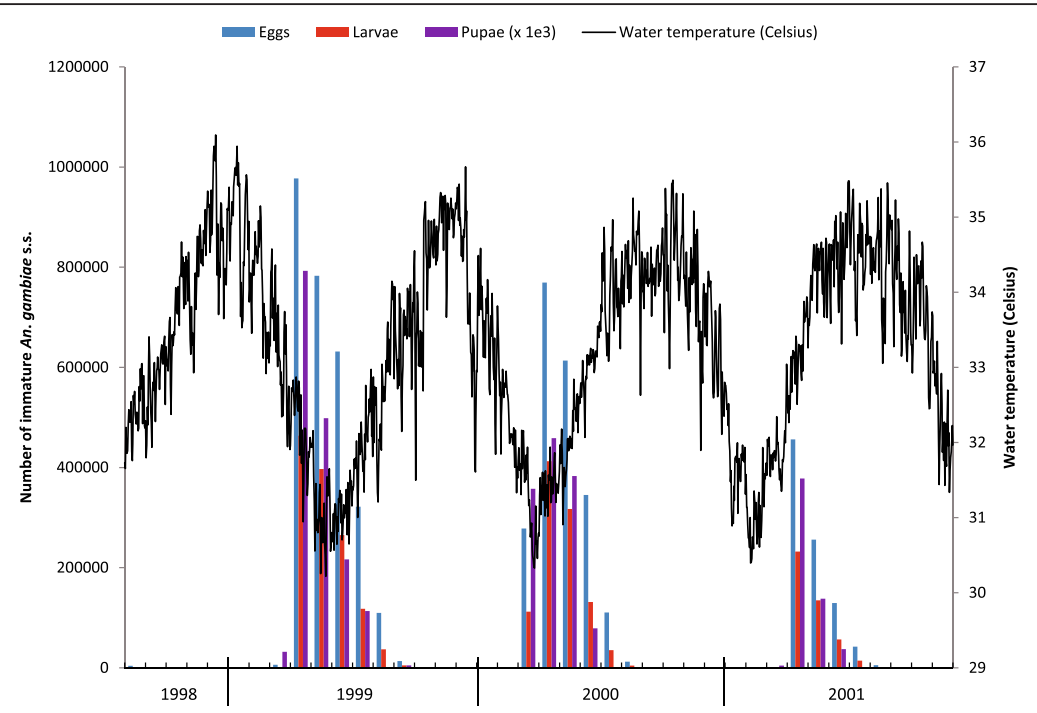

Figure 9 Water temperature behaviour and dynamics of the number of eggs, larvae, and pupae over the calibration and validation periods. 


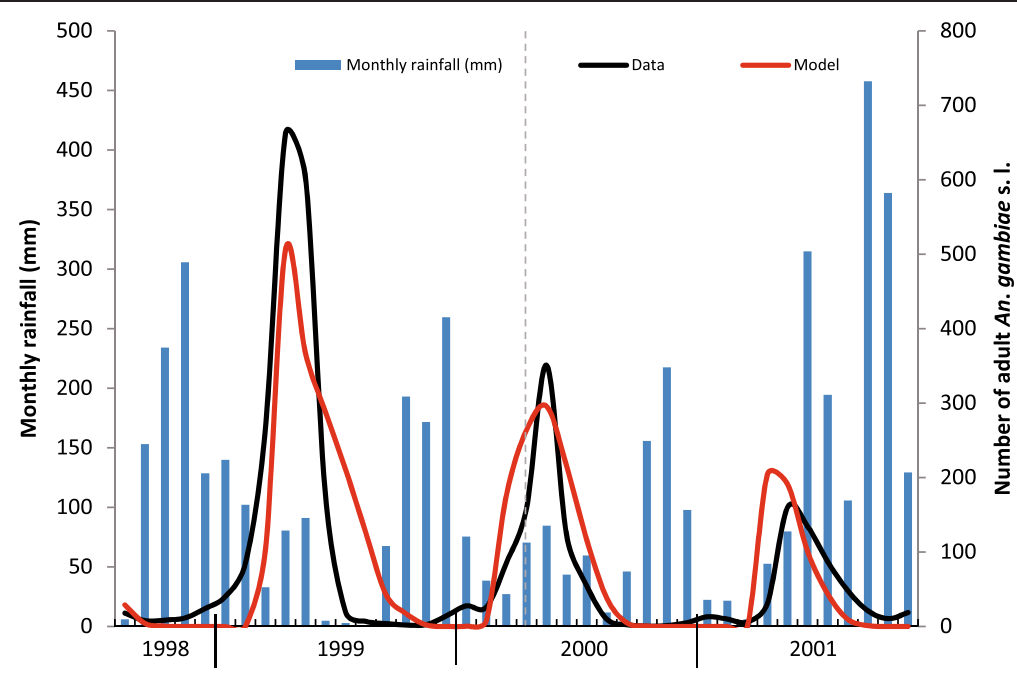

Figure 10 Model fitting against all 40 (complete) months of adult An. gambiae s.l. abundance data in [13].

role of both is key, particularly in the context of how climate change may influence the future spread and distribution of VBDs. Here, a useful framework for understanding how changes in rainfall, temperature, $\mathrm{RH}$, wind speed and cloudiness (both mean values and temporal variability), and density-dependence, at breeding sites may influence vector abundance is presented. By calibrating and validating the model against longitudinal abundance data, this framework is shown to be capable of reproducing the observations in [13] on long-term timescales, suggesting a mechanistic underpinning of mosquito dynamics in terms of environmental variables, an important result given the ongoing debate regarding the link between malaria transmission and climatic changes in Africa [3,4]. This work also highlights the power of mathematical models in addressing key questions surrounding the role of environmental variables, compared to the multitude of other ecological, epidemiological, socioeconomic and demographic factors, on disease transmission [1]. An important advance of this work is the construction of a modeling framework enabling the linkage of climatic events at large spatial scales to processes at the localized scale of vector breeding sites, enabling assessments of how climatic phenomena at different scales may affect disease transmission in host communities.

Model reliability may be enhanced with improved parameterization and future experimental and modeling research will lead to further understanding of speciesspecific Anopheles population dynamics and their response to environmental variables. These include (i) improving our understanding of Anopheles oviposition behaviour, (ii) better quantifying the role of rainfall and temperature on egg, larval and pupal survival, as well as the role of heterogeneities, such as body size, that might influence response, (iii) improved modeling of the relationship between air and water temperatures at breeding sites, (iv) improving our understanding of densitydependent effects on juvenile and adult development and survival (including intra-specific competition, interspecific interactions between species, cannibalistic tendencies, and predation, as well as their dependence on climatic variables), (v) assessing evidence for agedependent mortality in juveniles and adults, and (vi) better understanding variability in gonotrophic cycles.

New longitudinal vector studies that simultaneously measure changes in environmental variables are also required to improve the validity and reliability of vector models, which will not only further our understanding of dominant factors driving mosquito dynamics, but will also improve our understanding of the implications for VBD transmission. Nonetheless, the approach here not only provides a useful framework for An. gambiae s.s. modeling, but its structure may be readily applied to other Anopheles species with suitable parameterization, as well as other vectors (such as Aedes or Culex). This will ultimately enable a better understanding of the response of a variety of VBDs to environmental change, an important question given the likely influences of weather and climate on many regions of VBD risk over the coming decades.

\section{Competing interests}

The authors declare that they have no competing interests, financial or otherwise.

\section{Authors' contributions}

PEP conceived of the study design and framework, directed the research and wrote the manuscript. DP and CCJ both made significant contributions to the parameterization work, components of the model, and data fitting. SL contributed multiple unpublished datasets and parameterization work. WH contributed computational assistance in multiple phases of the project. EM contributed to the concept of the study. All authors read and approved the final manuscript. 


\section{Acknowledgements}

The authors would like to thank Henri Tsila for providing unpublished data that formed the basis of Figure 4. PEP and EM would like to thank the Grantham Institute of Climate Change at Imperial College London for funding this research. EM also acknowledges the Eck Institute for Global Health at the University of Notre Dame for part funding this work. None of the funding bodies mentioned contributed to the design, collection, analysis or interpretation of data, nor the writing of the manuscript or decision to submit. The authors would like to thank the two anonymous reviewers whose comments greatly improved this manuscript.

\section{Author details}

'Grantham Institute for Climate Change, Department of Infectious Disease Epidemiology, Imperial College, London W2 1PG, UK. ${ }^{2}$ Department of Infectious Disease Epidemiology, Imperial College, London W2 1PG, UK. ${ }^{3}$ Disease Control and Vector Biology Unit, London School of Hygiene and Tropical Medicine, London WC1E 7HT, UK. ${ }^{4}$ Department of Biological Sciences, University of Notre Dame, Notre Dame, IN 46556-0369, USA.

Received: 4 April 2012 Accepted: 31 July 2012

Published: 9 August 2012

\section{References}

1. McMichael A, Woodruff R, Hales S: Climate change and human health: present and future risks. Lancet 2006, 367:859.

2. WHO: The global burden of disease: 2004 update. Geneva: World Health Organization; 2008

3. Hay SI, Cox J, Rogers DJ, Randolph SE, Stern DI, Shanks GD, Myers MF, Snow RW: Climate change and the resurgence of malaria in the East African highlands. Nature 2002, 415:905-909.

4. Pascual M, Ahumada JA, Chaves LF, Rodo X, Bouma M: Malaria resurgence in the East African highlands: temperature trends revisited. Proc Natl Acad Sci USA 2006, 103:5829-5834.

5. Craig MH, Snow RW, le Sueur D: A climate-based distribution model of malaria transmission in sub-Saharan Africa. Parasitol Today 1999, 15:105-111.

6. Rogers DJ, Randolph SE: The global spread of malaria in a future, warmer world. Science 2000, 289:1763-1766.

7. Ermert V, Fink A, Jones A, Morse A: Development of a new version of the Liverpool Malaria Model. II. Calibration and validation for West Africa. Malar J 2011, 10:62

8. Hoshen MB, Morse AP: A weather-driven model of malaria transmission. Malar J 2004, 3:32

9. Martens P: Health and climate change: modeling the impacts of global warming and ozone depletion. Oxford, UK: Earthscan; 1998:176.

10. Depinay J-M, Mbogo C, Killeen G, Knols B, Beier J, Carlson J, Dushoff J, Billingsley P, Mwambi H, Githure J, Toure A, McKenzie F: A simulation model of African Anopheles ecology and population dynamics for the analysis of malaria transmission. Malar J 2004, 3:29.

11. Ermert V, Fink A, Jones A, Morse A: Development of a new version of the Liverpool Malaria Model. I. Refining the parameter settings and mathematical formulation of basic processes based on a literature review. Malar J 2011, 10:35.

12. White MT, Griffin JT, Churcher TS, Ferguson NM, Basanez MG, Ghani AC: Modelling the impact of vector control interventions on Anopheles gambiae population dynamics. Parasit Vectors 2011, 4:153.

13. Meyrowitsch DW, Pedersen EM, Alifrangis M, Scheike TH, Malecela MN, Magesa SM, Derua YA, Rwegoshora RT, Michael E, Simonsen PE: Is the current decline in malaria burden in sub-Saharan Africa due to a decrease in vector population? Malar $J$ 2011, 10:188.

14. Crouse DT, Crowder LB, Caswell H: A stage-based population model for loggerhead sea turtles and implications for conservation. Ecology 1987, 68:1412-1423.

15. Diuk-Wasser MA, Toure MB, Dolo G, Bagayoko M, Sogoba N, Traore SF, Manoukis $\mathrm{N}$, Taylor CE: Vector abundance and malaria transmission in rice-growing villages in Mali. Am J Trop Med Hyg 2005, 72:725-731.

16. Koenraadt CJM, Githeko AK, Takken W: The effects of rainfall and evapotranspiration on the temporal dynamics of Anopheles gambiae s.s. and Anopheles arabiensis in a Kenyan village. Acta Trop 2004, 90:141-153.
17. Allen RG, Pereira LS, Raes D, Smith M: Crop evapotranspiration - Guidelines for computing crop water requirements. FAO Irrigation and drainage paper 56. Rome: FAO - Food and Agriculture Organization of the United Nations; 1998.

18. ECMWF: data-portal.ecmwfint data-portal.ecmwf.int

19. Sinka ME, Bangs MJ, Manguin S, Coetzee M, Mbogo CM, Hemingway J, Patil AP, Temperley WH, Gething PW, Kabaria CW, Okara RM, Van Boeckel T, Godfray HC, Harbach RE, Hay SI: The dominant Anopheles vectors of human malaria in Africa, Europe and the Middle East: occurrence data, distribution maps and bionomic precis. Parasit Vectors 2010, 3:x117.

20. Bi P, Tong S, Donald K, Parton $\mathrm{K}, \mathrm{Ni}$ J: Climatic variables and transmission of malaria: a 12-year data analysis in Shuchen County. China. Public Health Reports 2003, 118:65.

21. Gimnig JE, Ombok M, Kamau L, Hawley WA: Characteristics of larval anopheline (Diptera: Culicidae) habitats in Western Kenya. J Med Entomol 2001, 38:282-288

22. McCrae AW: Oviposition by African malaria vector mosquitoes. II. Effects of site tone, water type and conspecific immatures on target selection by freshwater Anopheles gambiae Giles, sensu lato. Ann Trop Med Parasitol 1984, 78:307-318.

23. Munga S, Minakawa N, Zhou G, Barrack OO, Githeko AK, Yan G: Effects of larval competitors and predators on oviposition site selection of Anopheles gambiae sensu stricto. J Med Entomol 2006, 43:221-224.

24. Sumba LA, Ogbunugafor CB, Deng AL, Hassanali A: Regulation of oviposition in Anopheles gambiae s.s.: role of inter- and intra-specific signals. J Chem Ecol 2008, 34:1430-1436.

25. Sumba LA, Okoth K, Deng AL, Githure J, Knols BG, Beier JC, Hassanali A: Daily oviposition patterns of the African malaria mosquito Anopheles gambiae Giles (Diptera: Culicidae) on different types of aqueous substrates. J Circadian Rhythms 2004, 2:6.

26. Kramer WL, Mulla MS: Oviposition attractants and repellents of mosquitoes: oviposition responses of Culex mosquitoes to organic infusions. Environ Entomol 1979, 8:1111-1117.

27. Paaijmans KP, Wandago MO, Githeko AK, Takken W: Unexpected high losses of Anopheles gambiae larvae due to rainfall. PLoS One 2007, 2:e1146.

28. Romoser W, Lerdthusnee K, Berry R, Kittayapong P: Effect of mechanical shock on hydrostatic balance and survival of mosquito pupae. J Am Mosa Control Assoc 1994, 10:10

29. Koenraadt CJ, Paaijmans KP, Githeko AK, Knols BG, Takken W: Egg hatching, larval movement and larval survival of the malaria vector Anopheles gambiae in desiccating habitats. Malar J 2003, 2:20.

30. Beier JC, Copeland R, Oyaro C, Masinya A, Odago WO, Oduor S, Koech DK, Roberts CR: Anopheles gambiae complex egg-stage survival in dry soil from larval development sites in western Kenya. J Am Mosq Control Assoc 1990, 6:105-109.

31. Shililu II, Grueber WB, Mbogo CM, Githure Jl, Riddiford LM, Beier JC: Development and survival of Anopheles gambiae eggs in drying soil: influence of the rate of drying, egg age, and soil type. J Am Mosa Control Assoc 2004, 20:243-247.

32. Huang J, Walker ED, Vulule J, Miller JR: Daily temperature profiles in and around Western Kenyan larval habitats of Anopheles gambiae as related to egg mortality. Malar I 2006, 5:87.

33. Bayoh MN, Lindsay SW: Effect of temperature on the development of the aquatic stages of Anopheles gambiae sensu stricto (Diptera: Culicidae). Bull Entomol Res 2003, 93:375-381.

34. Kirby MJ, Lindsay SW: Effect of temperature and inter-specific competition on the development and survival of Anopheles gambiae sensu stricto and An. arabiensis larvae. Acta Trop 2009, 109:118-123.

35. Bayoh MN, Lindsay SW: Temperature-related duration of aquatic stages of the Afrotropical malaria vector mosquito Anopheles gambiae in the laboratory. Med Vet Entomol 2004, 18:174-179.

36. Armstrong JA, Bransby-Williams WR: The maintenance of a colony of Anopheles gambiae, with observations on the effects of changes in temperature. Bull World Health Organ 1961, 24:427-435.

37. Paaijmans K, Jacobs A, Takken W, Heusinkveld B, Githeko A, Dicke M, Holtslag A: Observations and model estimates of diurnal water temperature dynamics in mosquito breeding sites in western Kenya. Hydrological Processes 2008, 22:4789-4801. 
38. Tsila HaM J, Foko Dadji GA: Adaptative responses of Anopheles gambiae in crowding larvae conditions in laboratory. Asian J Biol Sci 2011, 4:259-265.

39. Service MW: Mortalities of the immature stages of species $B$ of the Anopheles gambiae complex in Kenya: comparison between rice fields and temporary pools, identification of predators, and effects of insecticidal spraying. J Med Entomol 1977, 13:535-545.

40. Gimnig JE, Ombok M, Otieno S, Kaufman MG, Vulule JM, Walker ED: Density-dependent development of Anopheles gambiae (Diptera: Culicidae) larvae in artificial habitats. J Med Entomol 2002, 39:162-172.

41. Mogi M, Miyagi I, Cabrera BD: Development and survival of immature mosquitoes (Diptera: Culicidae) in Philippine rice fields. J Med Entomol 1984, 21:283-291.

42. Koenraadt CJ, Takken W: Cannibalism and predation among larvae of the Anopheles gambiae complex. Med Vet Entomol 2003, 17:61-66.

43. Service MW: Studies on sampling larval populations of the Anopheles gambiae complex. Bull World Health Organ 1971, 45:169-180.

44. Brannstrom A, Sumpter DJ: The role of competition and clustering in population dynamics. Proc Biol Sci 2005, 272:2065-2072.

45. Mogi M, Okazawa T, Miyagi I, Sucharit S, Tumrasvin W, Deesin T, Khamboonruang C: Development and survival of anopheline immatures (Diptera: Culicidae) in rice fields in northern Thailand. J Med Entomol 1986, 23:244-250

46. NCDC: www.ncdc.noaa.gov.

47. Lindsay SW, Birley MH: Climate change and malaria transmission. Ann Trop Med Parasitol 1996, 90:573-588

48. Kirby MJ, Lindsay SW: Responses of adult mosquitoes of two sibling species, Anopheles arabiensis and A-gambiae s.s. (Diptera: Culicidae), to high temperatures. Bull Entomol Res 2004, 94:441-448.

49. Parham PE, Michael E: Modeling the effects of weather and climate change on malaria transmission. Environ Health Perspect 2010, 118:620-626.

50. Warrell DA, Gilles HM (Eds): Essential malariology. 4th edition.; 2002:xii + 348

51. Gillies MT, Wilkes TJ: A study of the age-composition of populations of Anopheles gambiae Giles and A. funestus Giles in North-Eastern Tanzania. Bull Entomol Res 1965, 56:237-262.

52. Clements $A$, Paterson $\mathrm{G}$ : The analysis of mortality and survival rates in wild populations of mosquitoes. J Appl Ecology 1981, 18:373-399.

53. Charlwood J, Smith T, Kihonda J, Heiz B, Billingsley P, Takken W: Density independent feeding success of malaria vectors (Diptera: Culicidae) in Tanzania. Bull Entomol Res 1995, 85:29-35.

54. Caswell H: Matrix population models: Construction, analysis, and interpretation. 2nd edition. Sunderland: Sinauer Associates, Inc; 2001.

55. Ferguson HM, Dornhaus A, Beeche A, Borgemeister C, Gottlieb M, Mulla MS, Gimnig JE, Fish D, Killeen GF: Ecology: a prerequisite for malaria elimination and eradication. PLOS Med 2010, 7:e1000303.

doi:10.1186/1475-2875-11-271

Cite this article as: Parham et al: Modeling the role of environmental variables on the population dynamics of the malaria vector Anopheles gambiae sensu stricto. Malaria Journal 2012 11:271.

\section{Submit your next manuscript to BioMed Central and take full advantage of:}

- Convenient online submission

- Thorough peer review

- No space constraints or color figure charges

- Immediate publication on acceptance

- Inclusion in PubMed, CAS, Scopus and Google Scholar

- Research which is freely available for redistribution 